\title{
Negotiate Your Commercial Lease or Renewal for Optometry Tenants
}

\section{Jeff Grandfield and Dale Willerton}

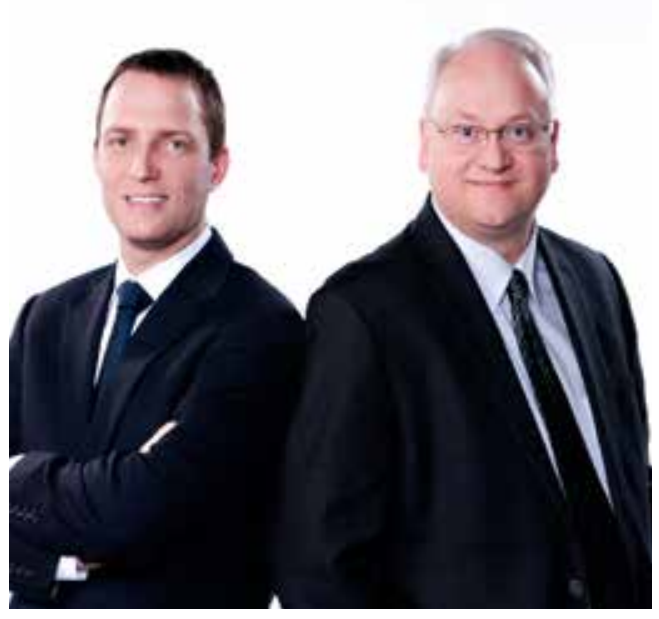

Dale Willerton is the founder of The Lease Coach and Jeff Grandfield recently joined him as partner. Dale and Jeff are commercial lease consultants who work exclusively for tenants, and are also professional speakers and co-authors of Negotiating Commercial Leases and Renewals For Dummies. Got a leasing question? Need help with your new lease or renewal? Call 1-800-738-9202, email DaleWillerton@TheLeaseCoach.com,or visit www.TheLeaseCoach.com. For a copy of our free CD, Leasing Dos \& Don'ts for Commercial Tenants, please email your request to DaleWillerton@TheLeaseCoach.com.

- 1 or many tenants, negotiating a good lease or lease renewal against an experienced agent

L or landlord can be a challenge. While an optometrist focuses on proper patient care, savvy real estate agents and brokers are specialized sales people. Their job is to sell tenants on leasing their location at the highest possible rental rate.

Optometry tenants may go through the leasing process two or three times in their entire lifetime - yet they have to negotiate against seasoned professionals who settle leases every day for a living. An appropriate lease term is vital for a tenant, because the amount of rent he or she pays will directly impact the clinic's financial bottom line.

Whether you are leasing a new location for the first time for your optometry clinic or you're negotiating a lease renewal, the following are some tips for tenants:

Negotiate to Win: All too frequently, optometry tenants enter into lease negotiations unprepared and don't even try to win the negotiation. If you are not even negotiating to win, you won't. With big commissions at stake, you can be sure the landlord's agent, on the other hand, is negotiating fiercely to win. Optometry tenants should remember it is okay to negotiate assertively.

Allow Sufficient Time: For a new location lease agreement, get started a minimum of nine months in advance to avoid unexpected situations and delays. Lease renewal negotiations should begin at least 15 months before the lease term expires. This will give you sufficient time to look at other sites, complete the necessary paperwork, and do your homework. If you can't get a decent renewal rate, would you rather move with three weeks or six months left on your lease term? Both for new leases and renewals, time will be your ally, or your enemy, depending on how you use it. 
Be Prepared to Walk Away: Set aside your emotions and make objective decisions. Whoever most needs to make a lease deal will give up the most concessions. A good clinic in a poor location will become a poor business.

Ask the Right Questions: Gathering information about what other tenants are paying for rent or what incentives they received will position you to get a better deal. Consider that your landlord and his agent know what every other tenant in the property is paying, so you must do your homework, too.

Brokers ... Friend or Foe? Real estate agents and brokers typically work for the landlord who is paying their commission. It is not normally the agent's role to get the optometry tenant the best deal; it is their job to get the landlord the highest rent, the biggest deposit, etcetera. Typically, the higher the rent you pay, the more commission the agent earns. If you are researching multiple properties, try to deal directly with the listing agent for each property, rather than letting one agent show you around or show you another agent's listing. Your tenancy is more desirable to the listing agent if he can avoid commission splitting with other agents.

Who Makes the First Offer? Whether you are looking at a new lease or a renewal, it is best if the landlord makes the first proposal. Don't be surprised if your verbal request (especially for a renewal proposal) falls on deaf ears. Write a brief letter (or email) to the leasing representative or property manager requesting a written proposal within ten days. Print a second copy of this letter or email for your records and to create a paper trail. If you make the first renewal offer, this implies you will stay leasing your current location, which undermines your negotiating strength.

Never Accept the First Offer: Even if the first offer seems reasonable, or you have no idea what to negotiate for, never accept the leasing agent`s first offer. In the real estate industry, most things are negotiable and the landlord fully expects you to counter-offer.

Go Slow for a Better Deal: Optometry tenants who rush a lease deal will often leave valuable incentives or inducements on the table. If you have the time available, we recommend that you take it. Often we get tenants more free rent, more tenant allowance, or even a lower rental rate just by refusing to sign too quickly on the dotted line. If the landlord or agent is anxious to close the deal, you can use stalling tactics to better your position (for example, saying that you're waiting on financing approval from the bank or you need to discuss matters with your business partner, who is currently out of town). Optometry tenants who have regrets will usually tell you that the whole leasing process happened so fast that they hardly realized what they agreed to.

Ask for More Than You Want: If you want three months free rent, then ask for five. No one ever gets more than they ask for. Be prepared for the landlord to counter offer and negotiate with you as well. Don't be afraid of hearing "no" from the landlord, as counter offers are all part of the game.

Negotiate the Deposit: Large deposits are not legally required in a real estate lease agreement for a tenant. Deposits are negotiable and, more so than anything else, often serve to compensate the landlord for the real estate commissions he will be paying out to the agents. If you are negotiating a lease renewal and your landlord is already holding a deposit of yours, negotiate to get that deposit back. The Lease Coach is frequently successful in negotiating for a reduced deposit (or none at all) for a new tenant and/or a refund of a paid deposit for existing tenants approaching their lease renewal.

Measure Your Space: Most optometry tenants who lease space pay rent per square foot. Frequently, the premises or area has not been measured properly and the tenant is paying for phantom space (or space that is reported but doesn't exist). Measurement discrepancies (more often made by accident or oversight rather than fraud) are common, so be sure to have your clinic's space verified. It not only affects your base/minimum rent but also your common area maintenance (CAM) costs. 
Lease Renewal Allowances: Optometry tenants often don't think they can negotiate for tenant allowance on their renewal term. Not true! Approximately $75 \%$ of our tenant clients get a tenant allowance (including free rent, landlord's work to the property, and so on). Remember, if the landlord is giving allowances to new tenants as enticement for moving in, then why can't you get an allowance, too? Even if your clinic space only needs cosmetic upgrades (e.g. new carpeting for the waiting room or a fresh coat of paint for your examination room), negotiate it as part of the renewal deal. After all, your tenancy is proven, plus there is less risk for the landlord putting cash into your renewal than taking a chance on a new tenant.

Anticipate Your Lease Assignment: Landlords anticipate you will eventually sell your clinic and that you will want to assign your lease agreement; you should do this, too! Some lease agreements state that the landlord can unilaterally terminate your lease rather than grant an assignment. On the other hand, the landlord can also automatically raise the rent for the new tenant (your clinic's buyer). Check this clause carefully before you agree to it - and then negotiate for changes.

Renewing With No Deposit: If your lease agreement requires you to make a deposit for the initial lease term, it is unacceptable for that deposit to continue indefinitely. Are you a security risk? Have your rental payments been made on time? If so, resist further security deposits and make sure this amendment is stated in the renewal document. Otherwise, your deposit, which was to be applied to the last month, needs to be replaced for the renewal term.

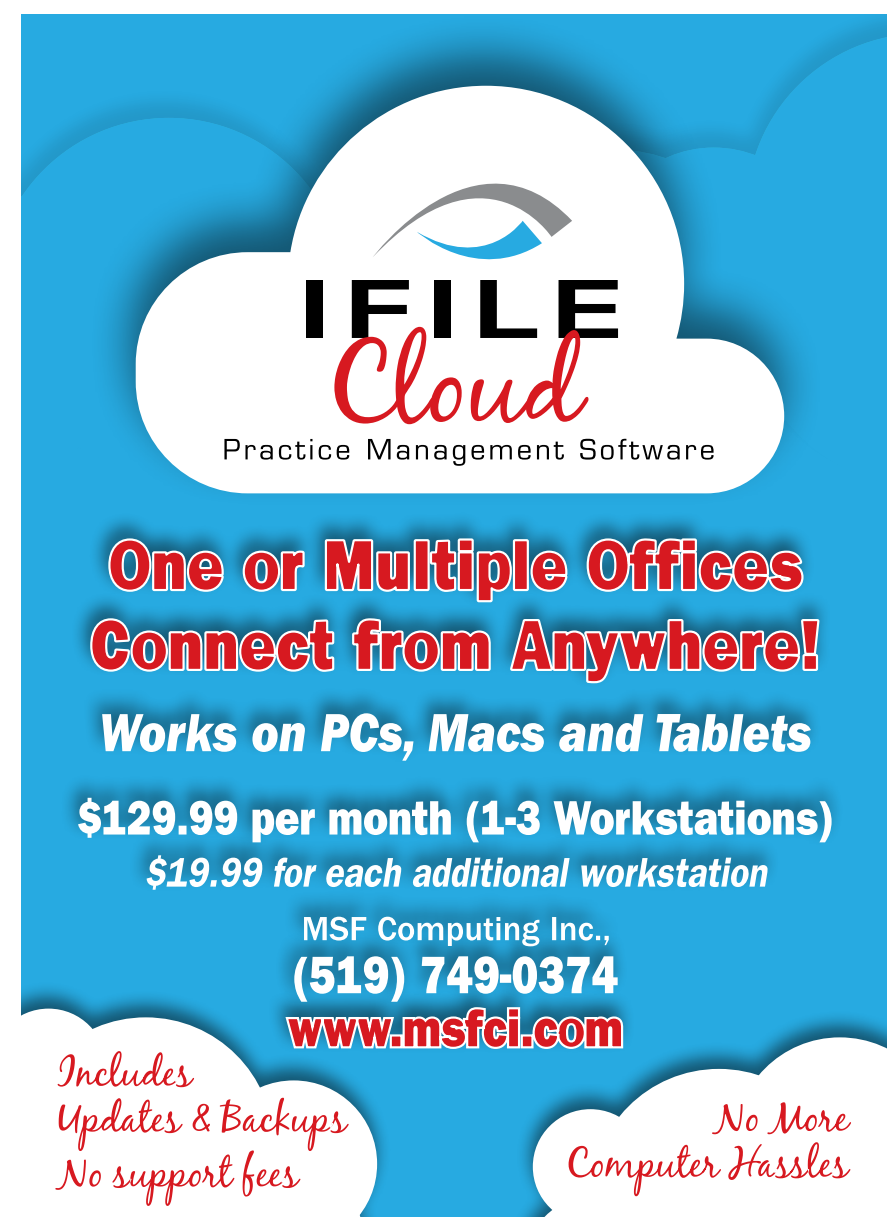

